\title{
OS FATORES REAIS DE PODER COMO OBSTÁCULOS AO ACESSO A EDUCAÇÃO DE QUALIDADE: ANÁLISE A PARTIR DO ATUAL CENÁRIO DOS CURSOS JURIDICOS NO BRASIL
}

Daury Cesar Fabriz ${ }^{1}$

Priscila Tinelli Pinheiro ${ }^{2}$

\section{Resumo}

A situação do ensino - em todas as suas etapas - enfrenta diversos problemas que contribuem com a sua precarização. Diante desta situação, o Estado implantou medidas, como o Plano Nacional da Educação (PNE), em busca de garantir o acesso da educação a todos. Todavia, tal medida contribuiu ainda mais para a crise enfrentada por todo o ensino superior jurídico - que constitui objeto do presente estudo - por aumentar de forma demasiada a oferta de vagas nos cursos jurídicos privados e públicos em todo o Brasil sem a devida estrutura. Para discutir tal situação, recorre-se à proposta de Ferdinand Lassalle acerca da análise do sistema jurídico brasileiro, em especial, a Constituição a partir da pressão exercida pelos "fatores reais de poder" constituídos por grupos sociais que buscam a prevalência de seus interesses em detrimento do interesse de toda a sociedade brasileira no ordenamento jurídico. Pretende-se analisar, por meio da pesquisa bibliográfica, quem são estes grupos que se apresentam como impedimentos ao acesso ao ensino superior de qualidade e contribuem com a manutenção do fenômeno da massificação dos cursos jurídicos. Propõe-se, então, investigar quais seriam as possíveis alternativas para se alcançar um ensino superior de qualidade sem restringir o acesso às classes mais baixas.

Palavras-chaves: Direito à Educação; Estado; Fatores Reais de Poder; Massificação; Ensino Jurídico.

\section{INTRODUÇÃO}

O direito à educação adquiriu o caráter de direito social fundamental com a promulgação da Constituição de 1988, haja vista a sua previsão no artigo $6^{0}$ - que trata dos direitos sociais. Constitui-se, também, em um direito de todos os brasileiros e, além disso, em um dever do Estado e da família, conforme o artigo 205 da Carta Magna.

\footnotetext{
${ }^{1}$ Doutorado em Direito pela Universidade Federal de Minas Gerais (2001). Presidente da Academia Brasileira de Direitos Humanos. Professor Doutor nível I da Faculdade de Direito de Vitória e professor associado III da Universidade Federal do Espírito Santo. E-mail: daury@terra.com.br

${ }^{2}$ Doutoranda em Direitos e Garantias Fundamentais pela Faculdade de Direito de Vitória (FDV). Membro do Grupo de Pesquisa Invisibilidade Social e Energias Emancipatórias em Direitos Humanos (FDV).E-mail: priscilatinelli@hotmail.com
} 
Diante da importância que a educação tomou com o texto constitucional de 1988, faz-se necessário analisar de que forma a educação vem sendo proporcionada para o brasileiro e, além disso, convém averiguar quais os possíveis problemas enfrentados para a concretização de tal ação, em especial, no nível superior. Optouse, desta forma, por analisar a situação do direito à educação nas instituições de ensino superior - sem olvidar que a maior parte dos problemas apresentados neste trabalho estão presentes em todos os níveis do ensino no Brasil.

Para tanto, traçou-se como principal objetivo a identificação dos obstáculos enfrentados para o fornecimento de uma educação superior de qualidade com o foco nas faculdades de Direito. Como objetivos secundários, almeja-se delinear o histórico dos cursos jurídicos no Brasil, os problemas enfrentados e possíveis ações que, se implementadas, potencializariam a função social do profissional do Direito.

Além disso, apresentar-se-á como a educação pode ser, ao mesmo tempo, um direito de todos e um dever do Estado e da família e, por conseguinte, em que tal previsão constitucional consiste, isto é, quais as medidas disponíveis aos órgãos estatais para o cumprimento desse dever constitucional.

Assim, por meio de uma abordagem dialética, almeja-se promover uma discussão acerca do atual cenário protagonizado pelos cursos jurídicos a partir da importância da educação no Brasil e dos "fatores reais de poder" que se apresentam, perante o sistema jurídico brasileiro, como os grandes impedidores ao acesso à educação superior de qualidade.

\section{EDUCAÇÃO COMO DIREITO DE TODOS E DEVER DO ESTADO}

O tratamento jurídico despendido à educação iniciou-se logo com a primeira Constituição Brasileira, em 1824. Naquele texto constitucional, estava prevista a gratuidade da instrução primária a todos os cidadãos e o ensino de ciências, belas letras e artes nos colégios e universidades por meio dos incisos XXXII e XXXIII do artigo 179 , respectivamente.

Observa-se que, apesar da inclusão da educação no âmbito constitucional, pouca relevância foi dada à matéria educacional, tendo em vista os ínfimos dispositivos legais destinados ao seu tratamento. Isto reflete o processo pelo qual a educação passou até chegar a ser positivada como um direito fundamental social, como consta na Carta Magna em vigor.

Destaca-se que este processo de incorporação da educação no âmbito constitucional foi lento, além de não ter seguido uma linearidade, na medida em que somente com o surgimento da Constituição de 1934 é que houve o reconhecimento da educação como um direito social, nos artigos 138 e 139. Contudo, a sua sucessora, "a Constituição Republicana de 1937 representou um corte ao caráter qualitativo da educação, por não mencioná-la como 'direito à educação" (TEIXEIRA, 2001, p. 131), mesmo tendo expresso nos demais dispositivos 
constitucionais o dever do Estado de executá-la.

Seguindo nesta retrospectiva, o "direito à educação" - outrora suprimido pelo texto constitucional retornou a este cenário com a Constituição Republicana de 1946, o que - nas palavras de Teixeira - "[...] representou um resgate do 'direito à educação', sendo garantido a todos e [...] como responsabilidade da família e do Estado, ao dispor da livre iniciativa particular" (2001, p. 131-132).

Ante o histórico constitucional apresentado, nota-se que foi somente com a promulgação da Constituição Federal de 1988 que a matéria educacional consagrou-se de forma efetiva como um direito social fundamental. Ao ser incorporado ao artigo $6^{\circ}$ da CFRB, entrou para o rol dos direitos sociais e no que tange ao mencionado status de direito fundamental, Barretto (2003, p. 124) aduz que:

[...] dentro de uma interpretação ética dos direitos humanos, fundada em valores intrínsecos à racionalidade humana, devem-se compreender os direitos sociais como direitos essenciais e inafastáveis, por conseguinte fundamentais. A partir dessa eticidade dos direitos humanos, pode-se falar em direitos fundamentais sociais, quais sejam, aqueles que, em vez de serem direitos contra o Estado, se constituem em direitos através do Estado, exigindo do Poder Público certas prestações materiais [...].

Com base no trecho citado e à luz da importância assumida pela educação na formação social, é possível classificá-la como mais que um direito social, uma vez que "[...] ínsita no direito à vida, é instrumento fundamental para que o homem possa se realizar como homem" (LINHARES, 2010, p. 108). Ou seja, constitui uma das bases para o exercício de outros direitos igualmente garantidos em âmbito constitucional.

Neste sentido, o constituinte de 1988 destinou um capítulo para tratar das especificidades que compreende a educação, qual seja o Capítulo III do Título VIII que se destina ao tema da educação, cultura e desporto. O primeiro dispositivo constitucional desta matéria - artigo 205 - dispõe que "a educação, direito de todos e dever do Estado e da família, será promovida e incentivada com a colaboração da sociedade, visando ao pleno desenvolvimento da pessoa, seu preparo para o exercício da cidadania e sua qualificação para o trabalho" (BRASIL, 2014).

É possível extrair diversas considerações a partir da redação deste artigo, mas por ora serão analisadas algumas questões que envolvem a natureza bifronte do conceito apresentado. O primeiro aspecto do conceito nos remete a ideia da educação como um direito de todos, o que significa que todos os brasileiros devem ter acesso à educação. Acerca disto, Tavares (2009, p. 836) faz uma ressalva no sentido de que:

Não se trata mais de qualquer direito à educação, mas daquele cujas balizas foram construídas constitucionalmente. Isso significa que o direito à educação é o direito de acesso, mas não um acesso a qualquer educação, e sim àquela que atende às preocupações constitucionais.

$\mathrm{O}$ autor nos conduz à refletir que a garantia do acesso do cidadão à educação deve ser aquela oferecida de forma qualitativa, ou seja, em conformidade com os preceitos constitucionais. Tais preceitos podem ser 
identificados ao longo do Capítulo III, por exemplo, no artigo 206 que elenca a garantia do padrão de qualidade (BRASIL, 2014) como um dos princípios em que o ensino será ministrado.

Em contrapartida, tem-se a dificuldade de se definir em que consiste um ensino de qualidade - questão que será aprofundada no próximo tópico que tratará do ensino jurídico - e sobre esta temática Oliveira e Araújo (2005, p.8) traçam o seguinte panorama:

De um ponto de vista histórico, na educação brasileira, três significados distintos de qualidade foram construídos e circularam simbólica e concretamente na sociedade: um primeiro, condicionado pela oferta limitada de oportunidades de escolarização; um segundo, relacionado à idéia de fluxo, definido como número de alunos que progridem ou não dentro de determinado sistema de ensino; e, finalmente, a idéia de qualidade associada à aferição de desempenho mediante testes em larga escala.

$\mathrm{Na}$ linha do que foi apresentado pelo autor, há várias formas de se medir a qualidade de ensino, entretanto - neste momento - será adotado o parâmetro estabelecido pela própria Constituição acerca do direito à educação, em que é considerado um ensino de qualidade aquele que visa "[...] ao pleno desenvolvimento da pessoa, seu preparo para o exercício da cidadania e sua qualificação para o trabalho" (BRASIL, 2014), o que se desdobra na seguinte reflexão:

Enfatizando-se o conceito de educação, entende-se esta por um processo de desenvolvimento da capacidade física, intelectual e moral da criança e do ser humano em geral, abrangendo, assim, todos os conhecimentos resultantes desse processo. A educação tem por objetivo propiciar a formação necessária ao desenvolvimento das aptidões, das potencialidades e da personalidade do educando. $O$ processo educacional tem por meta: (a) qualificar o educando para o trabalho; e (b) prepará-lo para o exercício consciente da cidadania. $\mathrm{O}$ acesso à educação é uma das formas de realização do ideal democrático (TEIXEIRA, 2001, p. 25).

O segundo aspecto contemplado pelo conceito fornecido pela Carta Magna é a educação como um dever, ao mesmo tempo, do Estado e da família. Destaca-se, desta forma, que:

Perante o direito à educação como direito fundamental ao Estado surge um dever de atuar positivamente, seja i) criando condições normativas adequadas ao exercício desse direito (legislação), seja, ii) na criação de condições reais, com estruturas, instituições e recursos humanos (as chamadas garantias institucionais relacionadas diretamente a direitos fundamentais) (TAVARES, 2009, p. 839).

Extrai-se - com base no trecho supracitado - que o Estado deverá atuar como garantidor do acesso à educação a todos, ou seja, ele deve criar mecanismos ${ }^{3}$ que deêm condições a todos os brasileiros de usufruir do ensino regular, o que está expresso no rol do artigo constitucional 208. Porém, é imprescindível que o acesso a este

\footnotetext{
${ }^{3}$ A título de exemplo de mecanismos estatais para a promoção da educação inclusiva, pode-se citar a determinação contida no inciso III, do artigo. 4ㅇ, da LDBN, o qual dispõe que: "o dever do Estado com a educação escolar pública será efetivado mediante a garantia de: III - atendimento educacional especializado gratuito aos educandos com necessidades especiais, preferencialmente na rede regular de ensino", bem como no inciso III do artigo 208 da CFRB/88. Tal medida representa um avanço - por parte do Poder Estatal - na garantia do acesso à educação às pessoas com necessidades especiais, mas não podemos olvidar das implicações que tal medida contempla, as quais, no cenário da educação brasileira atual, ainda não conseguiram ser efetivadas, tendo em vista a falta de capacitação dos professores e funcionários, bem como a falta de estrutura física para a promoção de tal política pública.
} 
ensino seja - como já mencionado - de qualidade e atenda aos preceitos estipulados pela Carta Magna de 1988.

Por outro lado, há o dever da família no cumprimento deste direito à educação -igualmente expresso no artigo $6^{\circ}$ da Lei de Diretrizes e Bases da Educação Nacional (LBDN no 9.394 de dezembro de 1996) - ao dispor que "é dever dos pais ou responsáveis efetuar a matrícula dos menores, a partir dos sete anos de idade, no ensino fundamental". Isto significa que não basta que o Estado forneça a educação - em atendimento aos preceitos constitucionais - se, em contrapartida, os pais não viabilizarem o ingresso de seus filhos nas redes regulares de ensino. Nesta medida, tanto a família - pais ou responsáveis pelo menor - quanto o Estado são igualmente responsáveis para a entrada de seus assistidos nestas instituições como forma de efetivação do direito à educação.

Com o objetivo de avançar nas especificidades contempladas pelo direito à educação e chegar nas discussões que envolvem o atual cenário dos cursos jurídicos no Brasil, faz-se necessária uma análise preliminar da educação no âmbito do ensino superior. Para tanto, a primeira consideração que deve ser feita diz respeito à autonomia concedida - pela Constituição Federal de 1988 - no artigo 207 às universidades. De acordo com o dispositivo constitucional, "as universidades gozam de autonomia didático-científica, administrativa e de gestão financeira e patrimonial, e obedecerão ao princípio de indissociabilidade entre ensino, pesquisa e extensão" (BRASIL, 2014).

Isto implica dizer que a autonomia conferida às universidades não é irrestrita, ou seja, ela deve ser exercida em conformidade com alguns parâmetros previstos na Carta Magna de 1988, bem como na LDBN de 1996. Um desses parâmetros - extraídos do próprio artigo 207 do texto constitucional - consiste no fato de que a referida autonomia deve ocorrer tão somente no âmbito didático-científico, administrativo e da gestão financeira e patrimonial. Acerca desta temática, Tavares (2009, p. 846) expõe que:

As três características da autonomia já mencionadas encontram-se fortemente interrelacionadas, pelo que o estudo de uma não pode ser realizado de maneira dissociada do das outras. Neste momento, pode-se conceituar autonomia como a impossibilidade de ingerência, dirigida ao Estado, quanto a todos aqueles assuntos que digam respeito à consecução das finalidades universitárias próprias. Deve ser respeitada, tanto pelo legislador quanto pelo administrador, a livre esfera de atuação de que desfrutam as universidades quando desempenham sua tarefa constitucional de oferecer o ensino, a pesquisa e a extensão.

Como segundo parâmetro para o exercício desta autonomia nas universidades, o texto constitucional elenca o princípio da indissociabilidade entre ensino, pesquisa e extensão. Destaca-se que tal princípio contempla o denominado tripé ensino-pesquisa-extensão, o qual representa uma verdadeira finalidade do ensino superior nos últimos anos. Contudo, é preciso ressaltar que tal princípio ainda não é aplicado de forma unânime e igualitária nas universidades brasileiras, o que constitui um indicador da precarização do ensino superior brasileiro.

Sobre a questão suscitada acerca da implantação desta política de fomento às pesquisa científica dentro das instituições de ensino superior, Linhares (2010, p. 117) acrescenta que "[...] sem o tripé fundamental 
ensino/pesquisa/extensão nos seus currículos, a universidade ficará sempre presa a valores políticas, éticos e jurídicos que se opõem a seus princípios fundamentais", tendo em vista que é preciso avançar no conhecimento e o espaço da academia é o mais apropriado para tal ação.

A preocupação com a efetivação do citado tripé educacional torna-se evidente também no artigo 43 da LDBN de 1996, o qual traz em seu bojo algumas das finalidades da educação superior e - dentre elas - está o fomento à pesquisa e à investigação científica, bem como à extensão, o que reflete os preceitos constitucionais.

Neste sentido, Tavares (2009, p.845) descreve, com base do texto constitucional de 1988, as funções das universidades por meio do perfil a elas atribuído, o que extrai-se da seguinte passagem:

A Constituição, ao tratar das universidades, atribui-lhes suas funções, com o que acaba por traçar-lhes um perfil mínimo de atuação. Além de sua finalidade fundamental, que é a promoção do ensino, as universidades devem implementar outras duas: a pesquisa e a extensão. É o que se depreende da leitura do art. 207, quando fala da indissociabilidade do ensino, pesquisa e extensão. É para fazer frente a essa função tão cara a qualquer povo ou país, em qualquer época da História, que as universidades foram dotadas de autonomia. Esta, pois, não é uma graça concedida pela Constituição sem qualquer motivo ou vinculação maior.

Nota-se, portanto, que é atribuído um alto valor ao incentivo pelas instituições superiores de ensino para a realização de pesquisas científicas interligadas ao ensino e à extensão. Ocorre que - como veremos adiante - a efetivação de tal proposta acadêmico-científica, dentre outras medidas potencializadoras do ensino superior, esbarra em obstáculos que, por vezes, impedem a sua concretização, por exemplo, a fiscalização precária exercida em especial - pelo Ministério da Educação.

\section{CURSOS JURÍDICOS NO BRASIL: DA CRIAÇÃO A MASSIFICAÇÃO}

Para ilustrar as questões postas em discussão pelo primeiro tópico acerca das especificidades que compõem o ensino superior, elegeu-se a situação dos cursos jurídicos no Brasil. Neste momento, portanto, far-se-á uma breve análise da criação destes cursos na sociedade brasileira por meio da apresentação das mudanças estruturais ocorridas daquela época em diante até chegar à atualidade.

Desta forma, o retorno à análise da criação dos cursos jurídicos no Brasil é necessário na medida em que o atual cenário educacional brasileiro traz em seu bojo demasiados resquícios da cultura que vigorava naquela época: formação de profissionais para compor a elite intelectual e cultural para conduzir o Estado brasileiro (BENTO; MACHADO, 2013, p. 201). Criou-se, então, instituições jurídicas com o objetivo de formar "[...] bacharéis que pudessem assumir os diversos cargos que a burocracia estatal ofertava, nos poderes administrativo, legislativo e judiciário (BENTO; MACHADO, 2013, p. 201).

Por ser a finalidade dos cursos jurídicos - tão somente - o fornecimento de profissionais capazes de conduzir a máquina estatal, o acesso ao ensino jurídico acabou tornando-se restrito às classes detentoras do poder, 
que visavam sua perpetuação nas instituições estatais, o que caracterizou "[...] o público alvo das faculdades de Direito, por anos a fio, [...] quase que exclusivamente composto por filhos das classes mais abastadas do país" (SANTOS, 2002, p. 36). Além disso, destaca-se que os primeiros cursos jurídicos foram criados nos centros urbanos - São Paulo e Olinda, o que representa um obstáculo ao acesso daqueles que não habitavam tais localidades, que em sua maior parte pertenciam às classes mais baixas.

E tal característica dos cursos jurídicos reflete os contornos assumidos pela educação superior brasileira em conformidade com as demandas típicas de cada contexto histórico enfrentado pelo país. Como pontuam os autores Bento e Machado (2013, p. 208-209), a análise da educação superior brasileira - em especial o ensino jurídico - pode se dar em três épocas distintas: o período colonial, a chegada da Corte Portuguesa ao Brasil e o período imperial, o que evidencia-se na seguinte passagem:

No período colonial, durante a fase do ensino executado pelas ordens religiosas, o sistema educacional superior teve como papel essencial formar os membros da classe religiosa e preparar para os estudos superiores na Europa os jovens que preferissem as profissões liberais, especialmente as vinculadas ao direitos e à medicina. Com a chegada da Corte Portuguesa ao Brasil, a função do ensino superior foi atender às necessidades da Corte portuguesa de formação dos membros de sua elite. No período imperial, a educação superior, especialmente a jurídica, contribuiu para a homogeneização da elite política, seguindo um padrão de formação elitista herdado de Portugal, além de ter preparado advogados, magistrados, funcionários públicos, jornalistas e diversos outros profissionais que o aparelho estatal e a sociedade da época exigiam (BENTO; MACHADO, 2013, p. 208209).

Nota-se, a partir do trecho em destaque, que as raízes do ensino jurídico estão atreladas ao contexto histórico do país, o qual reflete a realidade importada dos colonizadores europeus. Tem-se, desta forma, a incorporação das características típicas deste ensino jurídico elitista para a constituição das primeiras faculdades de Direito no Brasil ${ }^{4}$. Como já mencionado, o acesso às instituições superiores $\mathrm{e}-\mathrm{em}$ especial - as destinadas ao Direito não era democrático na medida em que se excluíam aqueles que não detinham determinado perfil para compor os quadros dos profissionais que deveriam ser formados por aquelas faculdades.

A partir desta situação, denota-se a existência de um elevado grau de distanciamento entre a realidade social - protagonizada pela sociedade brasileira da época - e o saber disseminado nos primeiros cursos jurídicos. Em primeiro lugar, houve o reflexo do aspecto físico, pois em virtude da localização destas instituições dar-se nos centros urbanos, não havia o contato com o cenário vivenciado pela grande massa da população brasileira, a qual - por sua vez - não habitava aqueles ambientes. Em segundo lugar, destaca-se a preocupação com a formação do profissional do Direito, a qual era direcionada à condução da máquina estatal e, por isso, exigia-se tão somente um

\footnotetext{
${ }^{4}$ Tal situação refletia os preceitos difundidos pelas Constituições Brasileiras, por exemplo, "com a Carta de 1937, o ensino de caráter profissionalizante é explicitamente incentivado, em consonância com o ideário político que embasava o Estado Novo" (SANTOS, 2002, p. 38).
} 
saber tecnicista, o que deixa novamente em evidência o completo afastamento do conhecimento proporcionado aos estudantes de Direito com a realidade social brasileira.

Sobre este ponto, Adeodato (2013, p. 566) traça a seguinte consideração acerca deste caráter tecnicista da formação jurídica - originado desde as primeiras faculdades de Direito - e ainda recorrente nos cursos jurídicos atuais:

Os cursos mantêm seu caráter bacharelesco, indiferentes às mudanças sociais e aos debates sobre elas, mostrando-se inadequados não apenas para explicar e transmitir conhecimentos sobre a realidade jurídica brasileira como também na preparação do aluno para a vida profissional prática.

Apesar desta situação ser típica daquele contexto histórico, ela ainda encontra-se presente em diversos cursos jurídicos atuais, o que revela - por completo - o descompasso entre a função para a qual o ensino superior e, principalmente, o jurídico foram criados e a que eles efetivamente estão exercendo. Acerca desta função, pode-se dizer que [...] a educação superior, especialmente a jurídica, possui um papel estratégico na formulação de um projeto de desenvolvimento sustentável; um desenvolvimento com justiça social e com respeito à cidadania (BENTO; MACHADO, 2013, p. 198).

Este paradigma começa a se transformar com a inclusão de algumas disciplinas propedêuticas na grade curricular dos cursos jurídicos, por exemplo, a Filosofia do Direito e a promover, por conseguinte, um conhecimento amplo e interdisciplinar para o estudante de Direito. Destaca-se, entretanto, que disciplinas como História, Economia e Filosofia já compunham os currículos dos primeiros cursos jurídicos, o que não se prolongou por muito tempo a fim de conceder espaço às disciplinas dogmáticas, as quais atendiam à formação tecnicista almejada naquele momento. Sobre esta situação, Santos (2002, p. 42) destaca que "a partir de 1966, esse panorama começa a se alterar, passando a predominar um enfoque positivista; retornam o Direito Romano (em 1971) e a Filosofia do Direito, e inclui-se a disciplina de Prática Forense, ainda que sem previsão legal para tanto".

Mas foi somente com a promulgação da intitulada Constituição Cidadã de 1988 - como já mencionado no tópico anterior - que o enfoque da educação, em sua dimensão macro (básica, fundamental e superior), passou a ser o pleno desenvolvimento da pessoa, seu preparo para o exercício da cidadania e sua qualificação para o trabalho, como preceitua o artigo 205 da CFRB/88. A inclusão destas especificidades nos leva a crer que a formação educacional - no que tange ao ensino superior - não se destina tão somente à formação técnica de um profissional, a qual - guardadas as devidas proporções - ainda é muito relevante para a composição do mercado de trabalho.

Deve-se ter em mente, desta forma, que a formação profissional adequada constitui-se pelo conhecimento técnico, mas se complementa - como afirma o dispositivo constitucional - com o desenvolvimento da pessoa e com o seu preparo para o exercício da cidadania. E, neste ponto, o Direito revela-se 
como um curso de demasiada importância para a sociedade, tendo em vista que ele pode vir "[...] para a transformação criativa do paradigma dominante, de modo a amenizar os problemas sociais sentidos na atualidade" (BORTOLON, 2010, p. 70).

Em consonância com os preceitos educacionais difundidos pela nova Constituição, pode-se citar uma transformação importante nos cursos jurídicos proporcionada pela edição da Portaria 1.886 do Ministério da Educação - MEC, em 1994. Por meio desta legislação, estabeleceu-se um conteúdo mínimo para a composição curricular dos cursos de Direito, dentre outras medidas, como a instituição do tripé ensino-pesquisa-extensão, a obrigatoriedade de apresentação e defesa de monografia final (art. 9º), além da criação de núcleos de prática jurídica coordenados por professores do curso $\left(\$ 1^{\circ} \text { do art. } 10^{\circ}\right)^{5}$.

Apesar de todas essas mudanças na regulamentação dos cursos jurídicos desde a sua criação até a atualidade, observa-se que elas pouco refletiram na formação dos novos estudantes de Direito, haja vista que algumas nem chegaram a ser implementadas por certas instituições, o que fomenta os diversos problemas ainda recorrentes na grande maioria das faculdades jurídicas do país. Para exemplificar algumas das causas que contribuem para a crise do ensino jurídico brasileiro, podemos citar as seguintes:

[...] a) o baixo nível do corpo docente, amadores recrutados de qualquer maneira na advocacia privada, na magistratura, no ministério público, muitos sem o menor preparo pedagógico, tornando o ensino jurídico uma atividade secundária, diletante e pessimamente remunerada; b) o baixo nível do corpo discente, selecionado a partir de um exame vestibular inapropriado e ignorante das necessidades do aluno [...]; c) [...] o ensino secundário mergulha em um pragmatismo que de pouco serve ao estudante após seu ingresso em determinadas faculdades, mormente as de direito; d) a proliferação do mercantilismo no ensino jurídico, tornando faculdades de direito um negócio fácil e lucrativo [...]; e) o estado caótico do ensino na maioria das escolas brasileiras de primeiro e segundo grau (ADEODATO, 2013, p. 566-567).

Diante das principais causas apresentadas pelo trecho supracitado, pode-se inferir que a crise no ensino jurídico é recorrente há anos e que mesmo com mudanças legais significativas os resquícios de uma formação tecnicista e resumida a interpretação e a aplicação de textos normativos continuam presentes nas faculdades de Direito.

No que tange esta permanente situação de crise protagonizada pelo ensino jurídico, Lênio Streck faz uma consideração no sentido de que antes desta ser uma crise do ensino é “[...] uma crise do Direito, que na realidade é uma crise de paradigmas, assentada em uma dupla face: uma crise de modelo e uma crise de caráter epistemológico" (2011, p. 97). E o autor explica que "de um lado, os operadores do Direito continuam reféns de

\footnotetext{
${ }^{5}$ Tais mudanças tiveram como objetivo a efetivação do tripé ensino-pesquisa-extensão, já previsto pela Constituição Federal de 1988 e instituído, pela Portaria 1.866, aos cursos de Direito, uma vez que a obrigatoriedade da apresentação de monografia final representa um incentivo à pesquisa na academia, bem como a criação dos núcleos de prática promovem a extensão do ensino das salas de aula com as demandas da população.
} 
uma crise emanada da tradição liberal-individualista-normativista (e iluminista, em alguns aspectos); e, de outro, a crise do paradigma epistemológico da filosofia da consciência” (STRECK, 2011, p. 97).

Em virtude deste cenário, "o resultado dessa(s) crise(s) é um Direito alienado da sociedade" (STRECK, 2011, p. 97), ou seja, o conhecimento que se aprende nos bancos das faculdades de Direito pouca utilidade terá para a solução dos conflitos sociais, tendo em vista que o saber técnico propriamente dito mostra-se - muitas vezes - insuficiente para dar uma resposta para as demandas apresentadas pela população.

Diante disto, faz-se necessário, então, a tentativa de se aproximar entre o Direito e a realidade social a qual ele está inserido, pois em virtude do caráter transformador contido nesta ciência, muitos dos problemas que afetam a sociedade brasileira poderiam ser resolvidos de maneira mais adequada por profissionais. Exige-se dos profissionais de Direito (advogados, promotores de justiça, juízes), desta forma, conhecimentos que vão além da dogmática e, em virtude destas situações, é possível afirmar que "[...] somente através da aproximação do direito com as demais áreas do conhecimento, tais como a Economia, a Sociologia, a Filosofia, a Ciência Política, dentre outras é que o profissional do direito poderá ser promotor de uma mudança social" (MARQUES, 2011, p. 112).

Em consonância com o exposto, Adeodato (2013, p. 575) salienta que:

[...] há nas faculdades de Direito o que se pode chamar de um isolamento doutrinário, pois a teoria jurídica dominante ainda é a mesma de décadas atrás e desconsidera contribuições de outras ciências sociais, fechando-se em um modelo epistemológico dogmático inadequado à realidade.

Isso significa que estudar as disciplinas jurídicas à luz dos fatores sociais que circundam toda a sociedade tem a capacidade de transformar o estudante do Direito em um profissional muito mais completo, pois, assim, privilegia-se, também, a questão da formação humanística ${ }^{6}$, a qual é tão carente nos atores jurídicos e ao mesmo tempo tão necessária para a solução dos conflitos sociais.

Este distanciamento estabelecido entre o Direito e a realidade social reflete-se até mesmo nos exemplos utilizados contidos nos livros, bem como naqueles utilizados pelos professores nas salas de aula para a contextualização das matérias jurídicas. Um exemplo recorrente ocorre no Direito Penal quando, para a explicação do instituto do estado de necessidade, utiliza-se os famigerados personagens de Caio e Tício protagonizando um naufrágio em alto-mar, em que "[...] sobem em uma tábua, e na disputa por ela, um deles é morto (em estado de necessidade, uma vez que a tábua suportava apenas o peso de um deles...!)” (STRECK, 2011, p.99).

\footnotetext{
${ }^{6}$ Resolução CNE/CES No 9/04: Art. 30. O curso de graduação em Direito deverá assegurar, no perfil do graduando, sólida formação geral, humanística e axiológica, capacidade de análise, domínio de conceitos e da terminologia jurídica, adequada argumentação, interpretação e valorização dos fenômenos jurídicos e sociais, aliada a uma postura reflexiva e de visão crítica que fomente a capacidade e a aptidão para a aprendizagem autônoma e dinâmica, indispensável ao exerćício da Ciência do Direito, da prestação da justiça e do desenvolvimento da cidadania.
} 
Ao apresentar este exemplo - típico no ensino jurídico - Lênio Streck (201 1, p. 99) traça uma crítica aos manuais e aos professores de Direito que poderiam promover uma contextualização das matérias jurídicas com a realidade social brasileira, mas estão presos a exemplos que - nas palavras do aludido autor - chegam a promover uma ficcionalização do mundo jurídico ao utilizarem casos que beiram ao folclórico. Em sua obra, o autor elenca o seguinte exemplo para apresentar o instituto penal do estado de necessidade aos alunos do curso de Direito: "[...] menino pobre entra no Supermercado Carrefour e subtrai um pacote de bolacha a mando de sua mãe, que não tem o que comer em casa [...]" (STRECK, 2011, p. 97).

A partir destas considerações acerca do distanciamento entre a ciência do Direito e a realidade social da sociedade brasileira, é inevitável que surja o questionamento acerca do porquê a ciência do Direito - mesmo contendo expressivo potencial transformador - não busca a compreensão da dinâmica social e baseia a sua prática neste sentido.

E, sobre esta indagação, a resposta parece ser clara quando analisamos que o referido potencial transformador do Direito pode apresentar-se como uma ameaça a toda a lógica dominante estatal e ao paradigma dogmático vigente, pois o "[...] lema do Estado Moderno é garantir a boa ordem, extirpando qualquer perigo de volta ao caos, mesmo que este 'perigo' sejam propostas emancipatórias" (BORTOLON, 2010, p. 74). Assim,

[...] o Direito acaba servindo como instrumento de regulação social, para a consequente manutenção da ordem estatal. Já no parâmetro científico, o Direito continua amarrado à ideia de autosuficiência, bem como se mantém na busca por dogmas inquestionáveis, por verdades abstratas e universais (BORTOLON, 2010, p. 74).

Conforme exposto, o cenário da crise no ensino jurídico não se resume a um problema curricular, tendo em vista que a instituição de um currículo mínimo para as faculdades de Direito não se mostrou suficiente para a transformação do ensino jurídico, pois, mesmo a inclusão de disciplinas tão caras a esta ciência demonstrando um avanço ainda encontra-se muito forte a cultura dos primeiros cursos jurídicos, que buscava a formação tecnicista deste profissional.

Dentre esse conjunto de fatores que contribui para a precarização do ensino jurídico, está a ausência de reflexão dos discentes acerca das normas jurídicas à luz dos fatores sociais. Seria, portanto, uma forma de incentivo desta prática reflexiva o fomento à concretização do tripé ensino-pesquisa-extensão nas faculdades de Direito de modo que o Direito possa acompanhar as mudanças protagonizadas pela sociedade, pois estas constituem o seu verdadeiro objeto de trabalho. Tal medida requer, portanto, uma prática diferenciada do estudante de Direito, por exemplo, a realização de pesquisas acadêmicas - que compõem o referido tripé -, e que estas, por sua vez, dediquem-se à compreensão dos fenômenos sociais.

Ocorre que, na prática, quando há esse incentivo à pesquisa esta segue a mesma lógica positivista difundida desde os primeiros cursos jurídicos brasileiros, ou seja, busca-se o conhecimento por meio de decisões 
judiciais, da análise de leis, mas é pouca reflexão crítica que é promovida por este tipo de pesquisa, além de não contribuir com o que deve ser sua principal finalidade: transformação do ensino jurídico em atendimento à realidade social brasileira. Esta situação está bem refletida na seguinte passagem:

[...] a pesquisa jurídica nas faculdades de direito, na graduação e na pós-graduação, é exclusivamente bibliográfica, como exclusivamente bibliográfica e legalista é a jurisprudência de nossos próprios tribunais [...]. Os juízes decidem com os que doutrinam, os professores falam da sua convivência casuística com os que decidem, os que doutrinam não reconhecem decisões. Esse é o trágico e paradoxal círculo viciosos da "pesquisa" jurídica tradicional; alienada dos processos legislativos (debates parlamentares, quando houve, a outra tragédia do autoritarismo), desconhece o fundamento de interesses das leis; alienadas das decisões continuadas dos tribunais, desconhece os resíduos dos problemas e do desespero forense do homem; alienada da verificação empírica, desconhece as inclinações e tendências da sociedade brasileira moderna (FARIA, 1987, p. 18).

Neste sentido, o que se denomina de massificação dos cursos jurídicos não se resume aos números alarmantes de alunos formados em Direito que ocorre a cada semestre no Brasil, mas sim o perfil com o qual este estudante está saindo da faculdade, ou seja, o que é preocupante é que essa "massa" de estudantes seja composta por meros reprodutores de leis e deficientes de qualquer capacidade crítica.

É inegável que os números contêm grande representação, pois a quantidade de faculdades de Direito crescem de maneira exponencial e, por isso, o mercado encontra-se tão saturado de profissionais jurídicos. Mas a preocupação deve voltar-se à qualidade desta formação, que - como demonstrado - não se mostra adequada à realidade brasileira.

Deve-se compreender, portanto, qual a lógica que impera em prol da manutenção da precarização do ensino jurídico, mesmo com a construção de faculdades privadas e aumento do número de vagas nas universidades públicas. Em contrapartida, tentar desvelar o porquê dessa "massa" de bacharéis não conseguir se inserir no mercado de trabalho, seja pela advocacia ou por alguma carreira pública. Sobre esta temática, o próximo tópico destina-se a discutir o que está por trás dessa realidade que os cursos jurídicos enfrentam, hoje, no Brasil com base na fiscalização, bem como no tipo de profissional que é formado pelas faculdades.

\section{OS FATORES REAIS DE PODER E O ACESSO AO ENSINO JURÍDICO DE QUALIDADE}

Após a apresentação da atual situação dos cursos jurídicos brasileiros a partir da análise constitucional direcionada ao direito à educação como direito de todos e dever do Estado, no presente tópico, pretende-se discutir acerca das situações que - por vezes - impedem que os brasileiros, ou pelos menos, grande parte deles, tenha acesso a um ensino superior de qualidade, cujo enfoque será dado no ensino jurídico.

Torna-se evidente, após a realidade exposta pelo segundo tópico, que o ensino superior - em especial o 
jurídico - faz parte de uma lógica mercantil, principalmente pela construção de faculdades privadas, em que é vendido um diploma de bacharel ao cliente, no caso o aluno de Direito, sem qualquer preocupação com a qualidade da formação que é conferida a ele.

Para compreender melhor o surgimento deste processo de mercantilização sofrido por todo o ensino superior brasileiro, é importante fazer uma retrospectiva no sentido de observar que o advento da Constituição de 1988 proporcionou a implementação, no país, de medidas destinadas a promoção do papel do Estado calcado em políticas sociais e de ajuste fiscal, o que representou forte avanço no que diz respeito ao controle e redução de gastos públicos. Destaca-se, ainda, que tal situação representou - no âmbito educacional - "[...] o acirramento das tensões entre as expectativas de melhoria da qualidade dos sistemas de ensino e a disponibilidade de recursos orçamentários para a consecução desse fim" (OLIVEIRA; ARAÚJO, 2005, p. 6).

Desenvolveu-se, nesta medida, uma compreensão de qualidade do ensino a partir de dois pilares: eficiência e produtividade trazendo em seu bojo uma perspectiva tipicamente empresarial e mercantilista "[...] em contraposição à idéia de democratização da educação e do conhecimento como estratégia de construção e consolidação de uma esfera pública democrática" (OLIVEIRA; ARAÚJO, 2005, p. 6).

Sobre isto, os autores Oliveira e Araújo (2005, p. 6-7) trazem os seguintes apontamentos:

[...] se até a década de 1980 podemos perceber certa identidade entre a ideia de qualidade e a ampliação das oportunidades de acesso aos serviços educacionais, a partir do princípio de justiça redistributiva dos bens sociais e econômicos, na década seguinte, esses princípios serão preteridos por aqueles ligados a uma lógica eminentemente empresarial, que enfatizam as idéias de maior produtividade, com menor custo e controle do produto.

Outro posicionamento - de igual relevância - acerca da demanda exacerbada de bacharéis em Direito é o de José Eduardo Faria por meio do qual o autor divide o processo denominado de "abastardamento do ensino superior" (1987, p. 19) em três momentos, os quais se moldam de acordo com contextos históricos específicos, senão vejamos:

Num primeiro momento, devido à intensidade do ritmo de desenvolvimento do país, especialmente a partir do processo de industrialização acelerada da segunda metade dos anos 60, estimulado por um autoritarismo burocrático-militar que julgava poder legitimar-se pela eficiência de sua gestão administrativa, o parque fabril, o setor de serviços e a própria administração pública - quer a direta que a indireta - passaram a criar novas e crescentes oportunidades de trabalho. Com a expansão econômica, os recém-diplomados conseguiram empregar-se quase que independentemente do que haviam aprendido em seus respectivos cursos de graduação. Isto ocorreu porque um grande número de atividades de "ensino superior" exigia, quando muito, habilidades bastante genéricas. E estas, na verdade, podiam ser obtidas mais pelo relacionamento social e pelo ambiente então vivido pelos estudantes do que propriamente pelo conteúdo dos programas e dos currículos universitários (FARIA, 1987, p. 19).

Seguindo a sua construção, o autor nos apresenta que:

Num segundo momento, já nos anos setenta, a absorção imediata e automática de uma 
grande massa de bacharéis com má formação acadêmica, dadas as prementes necessidades do mercado de trabalho em fase de crescimento, permitiu que a maioria dos sistemas educacionais se expandisse de maneira dissociada da realidade sócio-econômica nacional, criando sua própria burocracia, definindo com relativa autonomia o teor de seus cursos e diplomando sucessivas turmas de jovens cujo despreparo profissional era compensado pelos centros (empresariais ou governamentais) de treinamento, reciclagem e aperfeiçoamento de recursos humanos. Num terceiro momento, tal círculo vicioso tornou-se ainda mais acentuado com a progressiva tendência à "corporativização" da educação superior, mediante a monopolização das oportunidades de trabalho em nome da formação profissional, estimulando assim a criação de cursos e diplomas sem conteúdo cognitivo e técnico que o justificassem (FARIA, 1987, p. 19).

Em uma tentativa de modificação desta lógica de forma a viabilizar o acesso de todas as classes ao ensino superior, o governo criou o primeiro Plano Nacional da Educação - PNE, por meio da Lei no 10.172/2001, que possui - dentre outras - a meta de "[...] prover até o final dessa década, a oferta de Educação Superior para pelos menos 30\% da faixa etária de 18 a 24 anos" (LINHARES, 2010, p. 114). Tal plano teve diversas repercussões, sendo a principal delas o aumento do número de vagas na educação superior - seja pela construção de instituições privadas de ensino ou pelo aumento da disponibilidade nas universidades públicas.

Apesar disto, pode-se dizer que a abertura de faculdades de direito como está sendo realizada no Brasil nos últimos anos, longe de democratizar o ensino, prejudica sua qualidade. Nota-se que, conforme cresce o número de vagas nos cursos de Direito, há a redução da qualidade do ensino (BRITO, 2008, p. 78), pois há inúmeros fatores - os quais serão apresentados no decorrer deste tópico - que dificultam o atendimento desta vasta demanda de estudantes.

A partir desta afirmação, infere-se que a previsão constitucional de que a educação é um direito de todos nos induz a pensar que o Estado tem o dever de garantir a todos um montante de vagas que seja suficiente para atender a toda a população brasileira. Ocorre que isso não é possível sem que haja, por outro lado, uma compensação, ou seja, mesmo que o Estado possuísse condições para atender a todos com vagas no ensino superior, por exemplo, essa formação seria - em algum momento - deficitária como é a realidade que circunda, hoje, o ensino superior no Brasil.

É inegável, portanto, que o crescimento desenfreado de instituições de ensino superior - públicas ou privadas - coloca em risco o fornecimento de uma educação de qualidade, uma vez que permitir o acesso da população ao ensino não é garantia de que este seja de qualidade, tendo em vista a falta de suporte para acompanhar tamanha demanda, seja pela insuficiência de corpo docente qualificado ou mesmo pela estrutura física adequada.

Em virtude desta situação, pode-se afirmar que as políticas de "democratização da educação" não correspondem ao seu objetivo maior: fornecimento de uma educação de qualidade, uma vez que esta é concedida de forma meramente quantitativa. Assim, o Estado está, novamente, descumprindo o seu dever constitucional, 
que consiste em proporcionar uma formação educacional em consonância com os objetivos estabelecidos pela Carta Magna de $1988^{7}$.

A partir dessas considerações iniciais, convém salientar que toda a lógica mercantil, a qual a educação brasileira e, principalmente, os cursos jurídicos estão submersos não passa de um processo liderado pelos "empresários da educação" e que possui como outros atores o governo e a clientela. Sobre isto, Adeodato (2013, p. 568) explica que o fenômeno da massificação decorre da lógica observada pelos empresários, qual seja a de que os custos de uma educação jurídica de qualidade são elevados, o que não mostra-se vantajoso para uma empresa. Por isso, então, eles demonstram-se contrários à obrigatoriedade do exame de ordem ${ }^{8}$ e buscam cada vez mais o aumento do financiamento público com vista a elevar a demanda de seus alunos na iniciativa privada.

No que tange aos clientes - também protagonistas desta lógica empresarial - ressalta-se que eles apresentam-se convenientes “[...] com duas características praticamente incontornáveis a médio prazo: não dispõe de recursos para pagar por um curso de qualidade e traz deficiências da formação básica que o curso superior simplesmente não consegue superar" (ADEODATO, 2013, p. 568).

Disto decorre o fato de que as relações hierarquizadas sobre as quais a sociedade brasileira se constrói estão diretamente relacionadas à precarização do ensino, tendo em vista que os maiores prejudicados - como vimos - serão os que integram a base destas relações. Isto significa que aquelas classes ${ }^{9}$ que não possuem condições financeiras suficientes para adquirem uma boa educação básica e fundamental são, num segundo momento, impedidas de ingressar em uma universidade pública de qualidade - em virtude da deficiência nestas etapas iniciais da formação - não lhes restando opções senão aderir a faculdades que fornecem boas condições de pagamento e grande oferta de vagas.

Em terceiro lugar aparece a figura do governo - também como um dos atores que constituem o fenômeno da massificação - cujo interesse está “[...] na quantidade de jovens na universidade, para fazer frente a indicadores, também quantitativos, de organismos internacionais, e parte da mesma lógica: com exigências de

\footnotetext{
${ }^{7}$ Art. 206. O ensino será ministrado com base nos seguintes princípios: I - igualdade de condições para o acesso e permanência na escola; II - liberdade de aprender, ensinar, pesquisar e divulgar o pensamento, a arte e o saber; III - pluralismo de idéias e de concepções pedagógicas, e coexistência de instituições públicas e privadas de ensino; IV - gratuidade do ensino público em estabelecimentos oficiais; $\mathrm{V}$ - valorização dos profissionais da educação escolar, garantidos, na forma da lei, planos de carreira, com ingresso exclusivamente por concurso público de provas e títulos, aos das redes públicas; VI - gestão democrática do ensino público, na forma da lei; VII - garantia de padrão de qualidade; VIII - piso salarial profissional nacional para os profissionais da educação escolar pública, nos termos de lei federal (BRASIL, 1988).

8 "O exame de ordem, último bastião, ganha cada vez mais desafetos, mantido o presente status quo, pois aumenta e sempre aumentará o número de reprovados, um manancial de votos para políticos sem compromisso com a qualificação do profissional do direito, que argumentam que a $O A B$ pretende reserva de mercado para seus advogados já inscritos, como se os recursos oriundos de eventuais novos advogados em massa não fossem significativamente superiores aos recursos obtidos com exames de ordem, ou como se o mercado mesmo não se garantisse contra essa inflação de bacharéis" (ADEODATO, 2013, p. 574).
} 
qualidade, a ampliação de vagas será muito menor e muito mais lenta” (ADEODATO, 2013, p. 569).

O reflexo de toda esta situação descrita origina-se, na Constituição por meio da ação dos "fatores reais de poder", que são formados pelos “empresários da educação" apresentados. De acordo com Lassalle (2001, p. 10), estes "[...] fatores reais de poder que atuam no seio de cada sociedade são essa força ativa e eficaz que informa todas as leis e instituições jurídicas vigentes, determinando que elas possam ser, em substância, a não ser tal como elas são". Em outras palavras, o autor nos apresenta que a Constituição, bem como outras legislações esparsas que integram o sistema jurídico são frutos da atuação de determinados grupos sociais, os quais exercem pressão para que seus interesses encontrem-se devidamente protegidos e promovidos pelas regras jurídicas.

Estes grupos podem ser, segundo Lassalle, a monarquia, a aristocracia, a grande burguesia, os banqueiros, a pequena burguesia ou mesmo a classe operária. No caso do sistema educacional, temos a forte pressão exercida pelos intitulados "empresários da educação", os quais são os responsáveis pela transformação da educação em um produto, que no ensino superior, pode ser adquirido por meio de um mero diploma de bacharel em Direito. Observa-se, então, que:

Hoje, em grande parte dos cursos jurídicos, não se cursam disciplinas, mas "compram-se" créditos. É uma clara relação de compra e venda. O objeto de compra não é o conhecimento, mas o título cartorial que vai possibilitar determinado exercício profissional. Esse objeto é comprado pelo dinheiro das mensalidades e pelas avaliações favoráveis que devem ser alcançadas a qualquer preço. Assim, a relação educacional tornou-se mercantil e, tanto no que se refere à venda dos serviços educacionais pelas instituições privadas, quanto ás relações creditícias que regem a composição curricular de cada um dos estudantes. Logo, podemos dizer que os cursos jurídicos tornam-se um balcão de vendas, em que todas as características da mercadoria estão presentes. Há um constante dolus bonus em que o professor aparece como melhor do que realmente é e os alunos procuram pressioná-lo a fim de obter com maior rapidez a mercadoria que está sendo comprada a prazo (AGUIAR, 1999, p. 84).

A Constituição, desta maneira, apresenta como sua essência, "a soma dos fatores reais de poder que regem uma nação" (LASSALLE, 2001, p. 17), cujo processo de formação pode ser vislumbrado na seguinte passagem:

[...] juntam-se esses fatores reais de poder, os escrevemos em uma folha de papel e eles adquirem expressão escrita. A partir desse momento, incorporados a um papel, não são simples fatores reais de poder, mas sim verdadeiro direito - instituições jurídicas. Quem atentar contra eles atenta contra a lei e por conseguinte é punido (LASSALLE, 2001, p. 17 18).

Retira-se da pressão exercida por tal grupo ao governo, o porquê de não se modificar a lógica que rege o atual sistema educacional brasileiro - em especial o ensino superior jurídico - o qual pode ser resumido pela inviabilidade econômica e política que representa esta mudança. Nota-se, por um lado, que o potencial transformador do Direito acaba sendo "sufocado" em busca da manutenção do "[...] lema do Estado Moderno

\footnotetext{
${ }^{9}$ Destaca-se que "[...] a clientela das faculdades privadas constitui-se geralmente de pessoas de menor renda, menos preparadas,
} 
que é garantir a boa ordem, extirpando qualquer perigo de volta ao caos, mesmo que este 'perigo’ sejam propostas emancipatórias" (BORTOLON, 2010, p. 74). Logo, "[...] o Direito acaba servindo como instrumento de regulação social, para a consequente manutenção da ordem estatal" (BORTOLON, 2010, p. 74).

Diante do atual cenário presente nas faculdades de Direito, pode-se questionar acerca de quais seriam as possíveis medidas adotadas para a alteração da precarização do ensino jurídico proporcionado pela lógica mercantilista que impera. Para responder a tal pergunta, elegeu-se três aspectos julgados imprescindíveis ao aumento do nível dos cursos jurídicos atuais, são eles: investimento na formação do corpo docente, fomento à pesquisa acadêmica e, por último, aplicação de uma fiscalização rígida pelos órgãos responsáveis pelo ensino superior.

Com relação à formação do corpo docente, nota-se que a falta de incentivo - em especial o financeiro - a sua qualificação é cada vez mais premente, o que reflete diretamente na forma como os conteúdos são ministrados nas salas de aula. Ou seja, tem-se uma espécie de "pacto de mediocridade" 10 travado entre os alunos e os seus professores, em que vige a lógica do fornecimento de uma pseudo educação por meio da mera reprodução da legislação sem qualquer espécie de criticidade, por exemplo.

Divide-se, portanto, o atual corpo docente das faculdades de Direito em dois grupos sendo que:

[...] uma parte é de amadores que não vivem do ensino e tomam umas poucas turmas, para espairecer, ostentar o título de "professor" ou mesmo complementar a renda, mesmo que esse título e essa renda tenham efeitos cada vez menos significativos; outra parte já verificou que o conhecimento exigido para aquele nível de aulas é superficial e não demanda grandes investimentos de tempo e estudo; aí, dependendo de seu talento para agradas os alunos em aula, assumem 30 horas semanais de sala em uma ou diversas faculdades e conseguem um salário relativamente satisfatório; é contingente de professores com dedicação exclusiva às faculdades privadas (ADEODATO, 2013, p. 571-572).

Entretanto, não se deve vislumbrar o professor como único e principal agente transformador do ensino jurídico, pois de nada adianta ele chegar com práticas inovadoras - do ponto de vista metodológico - e a turma, em contrapartida - não aderir ao sistema de aula. Nesta medida, faz-se imprescindível que o aluno - como integrante do processo de aprendizagem - saia da zona de conforto que ocupa como mero receptor do saber jurídico e caminhe em busca de uma mudança de habitus, qual seja a realização de pesquisas.

Sendo, portanto, o conhecimento uma construção realizada de maneira conjunta pelos atores do processo de aprendizagem, nota-se a importância que a pesquisa assume nos cursos de Direito e, assim:

afastadas da universidade pública pela grande concorrência” (ADEODATO, 2013, p. 573).

${ }^{10}$ Vigora, neste pacto da mediocridade, a seguinte situação: "o professor finge que ensina e os alunos representam que aprendem". Essa farsa é garantida formalmente por outra - a da avaliação - na qual o professor, que pouco ou nada produz ou reproduz, pouco ou nada exige de seus alunos. Por sua vez, os alunos que sempre recebem avaliações favoráveis, nada exigem de seus professores" (AGUIAR, 1999, p. 84). 
Enquanto no ensino o aluno desempenha um papel passivo, de receptor de informações relatadas pelo professor, dentro da tipologia da aula-conferência, a pesquisa implica fazer o aluno buscar a informação por sua própria conta. E a palavra-chave para uma educação mais completa do estudante de direito é exatamente a problematização que caracteriza a pesquisa. Enquanto no ensino jurídico o objetivo é fazer o aluno ser capaz de compreender e dar de volta a informação recebida, ainda que com suas próprias palavras, na pesquisa o aluno precisa partir de um ou mais problemas específicos e daí desenvolver sua tese, que consiste exatamente na sugestão de uma resposta para aquele ou aqueles problemas (ADEOTADO, 2013, p. 565).

Como último aspecto necessário à transformação do ensino jurídico, aponta-se a questão da fiscalização sobre as instituições de ensino superior, a qual é de competência do Ministério da Educação - MEC tendo o próprio Conselho Federal da OAB como um ator secundário. Por meio das portarias criadas pelo MEC, é possível construir um padrão ideal para a criação, manutenção dos cursos jurídicos, bem como o aumento da oferta de vagas.

Apesar do estabelecimento de diversas regras para o funcionamento de cursos jurídicos em todo o país, observa-se que é recorrente a burla a tal fiscalização, o que justifica o grande número de instituições em perfeito funcionamento que formam profissionais em dissonância com o mercado para o qual ele se destina ou mesmo para exercer o verdadeiro papel que lhe cabe na sociedade.

Há, na verdade, um completo descaso - por parte dos órgãos estatais - no que diz respeito ao controle destas instituições. Percebe-se a facilidade com que as regras são desrespeitadas para que sejam cumpridos os requisitos para a abertura, manutenção do curso e, ainda, o aumento de vagas. Cita-se como formas de ludibriar estas regras o mascaramento da carga horária, da titulação dos professores e a implantação de bibliotecas de aluguel, as quais são instaladas da época em que é feita a fiscalização.

Importante ressaltar, todavia, que o Conselho Federal da $\mathrm{OAB}$ exerce um importante papel, nesta seara, uma vez que ele é responsável pela emissão de um parecer de caráter opinativo e não vinculativo acerca da abertura de cursos jurídicos no Brasil. Ocorre que, como mencionado, este parecer - mesmo sendo obrigatório no processo de autorização ou de reconhecimento do curso - não tem capacidade de obstar a decisão proferida pelo MEC sobre o assunto.

Ademais, dois instrumentos contribuem para uma espécie de controle de qualidade dos cursos jurídicos - mesmo contendo diversos problemas na sua realização, cuja discussão não é objeto do presente estudo - são eles: o Exame Nacional de Desempenho dos Estudantes - ENADE ${ }^{11}$ e o Exame de Ordem ${ }^{12}$ aplicado pela

\footnotetext{
${ }^{11}$ De acordo com o artigo 33-D da Portaria Normativa no 40 de 12/12/2007, o Exame Nacional de Desempenho de Estudantes (Enade), que integra o Sistema Nacional de Avaliação da Educação Superior (Sinaes), tem como objetivo aferir o desempenho dos estudantes em relação aos conteúdos programáticos previstos nas diretrizes curriculares do respectivo curso de graduação, e as habilidades e competências em sua formação.
} 
Ordem dos Advogados do Brasil - OAB.

Diante do exposto, é possível inferir que o ensino jurídico - há anos - passa por uma crise em decorrência do fenômeno da mercantilização do ensino, cujos principais responsáveis são os empresários que encontraram nas instituições de Direito uma fonte de renda para injetarem capital e obterem lucros. É preciso, portanto, a realização de uma profunda reforma no sistema de ensino jurídico brasileiro, o que requer, por conseguinte, a transformação dessa mentalidade que alimenta a acomodação por parte dos professores, alunos e poder estatal, pois enquanto a culpa pela precarização do ensino for concentrada em um único componente desta relação, não haverá melhora - nem se eles quisessem - uma vez que cada um possui a sua parcela de responsabilidade e tem condições, portanto, de modificar tal realidade.

\section{CONSIDERAÇÕES FINAIS}

Conforme apresentado, a educação é um direito fundamental social que aparece no texto constitucional de 1988 - ao mesmo tempo - como direito de todos e dever do Estado e da família. Isso significa que o Estado deve fornecer e criar mecanismos para que todos os brasileiros tenham acesso à educação, sendo que a obrigatoriedade de matrícula nas escolas, pelos pais, dirige-se à educação básica.

Entretanto, restou demonstrado que o dever do Estado em garantir o acesso à educação somente é cumprido no momento em que o ensino ofertado seja de qualidade, ou seja, mesmo se todos os brasileiros estiverem nas instituições de ensino e a educação for de má qualidade, ele não terá cumprido o seu dever constitucional.

E é justamente a má qualidade do ensino - em especial o superior jurídico - que discutiu-se neste trabalho, o qual, em virtude da disponibilização de uma exorbitante quantidade de vagas e das consequências advindas do fenômeno da mercantilização do ensino - com relação às faculdades privadas -, enfrenta uma profunda crise.

Neste sentido, identificou-se os "empresários da educação" - grupos econômicos que transformaram a educação em produto objeto de relações de compra e venda - como verdadeiros "fatores reais de poder", os quais exercem forte pressão para que a Constituição - incluído todo o sistema jurídico como um todo - represente os seus interesses. Tal situação tem se mostrado, desta forma, como um obstáculo ao acesso à educação de qualidade, já que no mercado almeja tão somente o aumento quantitativo do ensino, pois uma formação qualitativa - como demonstrou-se ao longo do trabalho - requer gastos que não seguem a lógica do lucro.

\footnotetext{
${ }^{12}$ É regulamentado pelo Conselho Federal da $\mathrm{OAB}$ e a aprovação constitui um requisito obrigatório para a inscrição do bacharel em Direito na Ordem dos Advogados do Brasil (artigo $8^{\circ}$ do Estatuto da OAB).
} 
Face a esta precarização do ensino jurídico - que impera o desestímulo dos professores quanto à formação continuada e implementação de técnicas pedagógicas inovadoras às aulas; alunos como clientes, que optam pela lei do menor esforço para adquirir o diploma; as instituições de ensino preocupadas em angariar cada vez mais alunos e manter o curso a baixo custo; e o governo como facilitador do acesso à educação a todos os brasileiros - é inegável a necessidade de reformulação.

Para tanto, é preciso que todos os atores da relação de ensino - alunos, professores, instituições de ensino, poder estatal - colaborem de modo a promover uma profunda mudança neste ciclo de massificação do ensino jurídico, já que o objetivo da formação de bacharéis em Direito - independente da quantidade - é o fornecimento de uma educação transformadora e potencializadora do caráter social que o Direito pode assumir.

\title{
THE REAL POWER FACTORS AS BARRIERS TO ACCESS TO QUALITY EDUCATION: ANALYSIS FROM THE CURRENT SCENARIO OF LEGAL COURSES IN BRAZIL
}

\begin{abstract}
The situation of education - in all its stages - faces several problems that contribute to their precariousness. In this situation, the State has implemented measures such as the National Education Plan (PNE), seeking to ensure education access to all. However, this measure further contributed to the crisis faced by the entire legal higher education - which is the subject of this study - to increase so too the offer of vacancies in the private and public law courses in Brazil without proper structure. To discuss such a situation, recourse to the proposal of Ferdinand Lassalle on the analysis of the Brazilian legal system, in particular the Constitution from the pressure exerted by the "real factors of power" made up of social groups seeking the prevalence of its interests in detriment of the interests of the Brazilian society in the legal system. We intend to analyze, through literature, who are these groups that stand as impediments to access to quality higher education and contribute to the maintenance of the mass phenomenon of legal courses. It is proposed then investigate what are the possible alternatives to achieve a quality higher education without restricting access to the lower classes.
\end{abstract}

Keywords: Right to Education; State; Real Factors of Power; Massification; Legal Education.

\section{REFERENCIAS}

ADEODATO, João Maurício. A OAB e a massificação do ensino jurídico. In.: SILVEIRA, Vladmir Oliveira da; SANCHES, Samyra Haydêe Dal Farra Naspolini; COUTO, Mônica Bonetti (Orgs.). Educação jurídica. São Paulo: Saraiva, 2013. p. 565-576.

AGUIAR, Roberto Armando Ramos de. A crise da advocacia no Brasil: diagnóstico e perspectivas. São Paulo: 
Alfa-Omega, 1999.

BARRETTO, Vicente de Paulo. Reflexões sobre os direitos sociais. In.: SARLET, Ingo Wolfgang (Org.). Direitos fundamentais sociais: estudos de direito constitucional internacional comparado. Rio de Janeiro: Renovar, 2003. p. 107-134.

BENTO, Flávio; MACHADO, Edinilson Donisete. Educação jurídica e fundação educacional. In.: SILVEIRA, Vladmir Oliveira da; SANCHES, Samyra Haydêe Dal Farra Naspolini; COUTO, Mônica Bonetti (Orgs.). Educação jurídica. São Paulo: Saraiva, 2013. p. 197-213.

BORTOLON, Mariana Cavarra. A necessidade de uma formação humanística efetiva no ensino do Direito. In.: FRANCISCHETTO, Gilsilene Passon Picoretti (Org.). Ensino jurídico e pedagogia: em busca de novos saberes. Curitiba: CRV, 2010.p. 53-76.

BRASIL. Constituição [da] República Federativa do Brasil. Disponível em: < http://www.planalto.gov.br/ccivil_03/constituicao/ConstituicaoCompilado.htm>.Acesso em: 02 de outubro de 2014 .

BRITO, Renato de Oliveira. O ensino jurídico no Brasil: análise sobre a massificação e o acesso aos cursos de direito. VIDYA, Santa Maria, v. 28, n. 2, p. 73-87, jul/dez, 2008.

FARIA, José Eduardo. A reforma do ensino jurídico. Porto Alegre: Sérgio Fabris, 1988.

LASSALLE, Ferdinand. A essência da constituição. 6. ed. Rio de Janeiro: Lumen Juris, 2001.

LINHARES, Monica Teresa Mansur. Ensino jurídico: educação, currículo e diretrizes curriculares no curso de Direito. São Paulo: Iglu, 2010.

MARQUES, Fabiano Lepre. A crise do ensino jurídico a partir do pacto da mediocridade: uma tentativa de superação através da formação docente. In.: FRANCISCHETTO, Gilsilene Passon Picoretti (Org.). Um diálogo entre ensino jurídico e pedagogia. Curitiba: CRV, 2011.p. 109-124.

OLIVEIRA, Romualdo Portela de; ARAÚJO, Gilda Cardoso de. Qualidade do ensino: uma nova dimensão da luta pelo direito à educação. Revista Brasileira de Educação. n. 28, 2005. p. 5-23.

SANTOS, André Luiz Lopes dos. Ensino jurídico: uma abordagem político educacional. Campinas: Edicamp, 2002.

STRECK, Lênio Luiz. Hermenêutica jurídica $\mathrm{e}(\mathrm{m})$ crise: uma exploração hermenêutica da construção do Direito. 10. ed. Porto Alegre: Livraria do Advogado, 2011.

TAVARES, André Ramos. Curso de direito constitucional. 7. ed. São Paulo: Saraiva, 2009.

TEIXEIRA, Eliana Franco. O direito à educação nas constituições brasileiras. Belém: UNAMA, 2001.

Trabalho enviado em 26 de agosto de 2016. 
Quaestio Iuris

Aceito em 16 de abril de 2017. vol. 11, no. 03, Rio de Janeiro, 2018. pp. 1398-1418 DOI: $10.12957 /$ rqi.2018.25279 